\title{
Serological screening tests for syphilis in pregnancy: results of a five year study (1983-87) in the Oxford region
}

\author{
P BOWELL, K MAYNE, * A PUCKETT, C ENTWISTLE, J SELKON $\dagger$ \\ From the Regional Blood Transfusion Centre, the *Department of Haematology, and $\dagger$ Public Health \\ Laboratory Services, John Radcliffe Hospital, Oxford
}

SUMMARY Between 1983 and 1987, 62 out of 76519 pregnancies in 51 mothers had a positive miniaturised Treponema pallidum haemagglutination assay (TPHA) test -1 in 1234 , or 0.81 per 1000 births. About two thirds of these mothers had syphilis and the remainder non-venereal treponematoses such as yaws or pinta. Antenatal screening identified 13 patients with previously unknown acquired syphilis, 11 of whom were given antibiotics during pregnancy. There were six fetal losses among the 62 TPHA positive pregnancies, but none had evidence of congenital syphilis. No live born child in this study group showed stigmata of congenital syphilis.

It is concluded that despite the current low incidence of syphilis in the United Kingdom it is imperative to continue antenatal serological screening and to emphasise the importance of early adequate treatment of the infection.

During pregnancy the causative organism of syphilis, Treponema pallidum, can cross the placenta and infect the fetus. Although the infection sometimes causes late abortion, many babies survive but show the stigmata of congenital syphilis. ${ }^{1-3}$

Congenital syphilis is no longer a major public health problem in the United Kingdom following the noticeable fall in acquired infections over the past 40 years. ${ }^{4}$ Since 1983 there have been less than five cases a year with no deaths among children under two years of age (CDSC, personal communication). The low incidence of congenital syphilis is probably largely due to the prompt treatment of early acquired syphilis and to the universal policy of screening pregnant women. ${ }^{145}$ Given this low incidence some have questioned the continuing benefit of the antenatal screening programme. ${ }^{6}$ In the United States, however, there has been a recent upsurge of acquired syphilis in women after a five year period of decreasing incidence, and the number of reported cases of congenital syphilis has increased from 115 in 1978 to 158 in $1983 .^{?}$

This essentially retrospective survey was undertaken to determine the incidence and clinical importance of positive TPHA tests and to assess the cost

Accepted for publication 13 July 1989 effectiveness of routine syphilis screening tests during pregnancy in the Oxford region.

\section{Patients and methods}

Blood samples from antenatal patients living in Oxfordshire, Northamptonshire, and north Buckinghamshire are referrred to the Oxford Regional Transfusion Centre (RTC) for antenatal serology tests. These routinely comprise: ABO and rhesus (D) blood group; screening tests for atypical red cell antibodies; hepatitis B (HBsAg) and treponemal infection (miniaturised TPHA). To obtain confirmation of blood group and to monitor for the development of atypical alloantibodies, Rhesus (D) negative patients are, on average, tested three times during pregnancy and those who are rhesus (D) positive twice.

The modified miniaturised spin TPHA test used at Oxford uses Fujirebio TPHA kits (Mast Diagnostics Ltd, Bootle, Merseyside), Terasaki plates, and a serum dilution of 1 in 10: the method is described in detail elsewhere. ${ }^{89}$ The cost of each TPHA screening test in 1988 was estimated at $6 p$ (reagent costs $1 p$; labour $4 p$; capital costs, overheads, and sundries $1 \mathrm{p}$ ).

Sera positive by the TPHA method are further tested both by Rapid Plasma Reagin (RPR), quantitatively after titration in physiological saline if necessary, ${ }^{8}$ and by TPHA using absorbed sera. Positive 
TPHA samples are referred to the Oxford regional reference laboratory of the Public Health Laboratory Services (PHLS) for confirmatory tests comprising Fluorescent treponemal antibody-absorbed (FTAABS), standard TPHA, and RPR tests. Only samples consistently FTA-ABS and TPHA positive are considered to be indicative of treponemal infection. Tests on cord blood samples, including IgG and IgM FTAABS tests, are independently arranged and carried out by the Oxford PHLS laboratory.

At the end of the study period a questionnaire, designed to determine whether the mother was known to have had a history of either syphilis or non-venereal treponemal infection, was sent confidentially to the attendant general practitioner. It was recognised, however, that the clinical diagnoses would most probably have been determined by local specialists in genitourinary medicine. Information was also sought regarding clinical presentation, previous treatment, ethnic origin and residence abroad, influence of a positive TPHA test on clinical management during pregnancy, and the outcome of pregnancy including details of serological tests performed on the baby. Additional data were obtained from hospital case notes where required.

This survey covered five years between 1983 and 1987. The number of births recorded during this period in the four health districts concerned was determined from Oxford regional health authority statistical sources.

\section{Results}

The total number of live births in the catchment area during the study period was 76519 . The number of pregnancies associated with a positive TPHA and FTA-ABS test result was 62 (one in 1234 or 0.81 per 1000 births) in 51 patients. One seropositive patient had three pregnancies during the study period and nine patients had two pregnancies.

Clinical data were not obtained for three patients who had moved from the Oxford region; information was incomplete for some of the remaining 48 patients. A definitive clinical diagnosis was available for 46 of these 48 patients and a laboratory interpreted diagnosis, based on medical history and serological data, was made for the other two (European) patients.

Of the $48,30(63 \%)$ had acquired syphilis, two $(4 \%)$ had congenital syphilis, and $16(33 \%)$ were regarded as having had yaws or pinta (table 1). Antenatal screening identified 13 patients with acquired syphilis (table 2) and another 13 patients in whom nonvenereal treponemal infections had been previously unsuspected. The serology of two patients with acquired syphilis was incorrectly regarded as false positive.

The clinicians reported the ethnic group or country of origin of 49 of the 51 patients; 25 being European, 16 from Afro/Caribbean countries, four from the Indian subcontinent, two from South America, and two from China or Vietnam.

The RPR remained negative throughout $36(58 \%)$ of the 62 pregnancies; a titre of $1 / 8$ or greater was seen in $10(16 \%)$ pregnancies, of which eight were associated with the clinical diagnosis by a venereologist of acquired syphilis and two with yaws.

As a result of antenatal screening it was decided to prescribe antibiotic treatment in $29(50 \%)$ of 58 pregnancies (table 1); one patient was given erythromycin, the remainder a penicillin. One baby was also given penicillin as a precautionary measure because of delayed treatment to the mother (table 2). Antibioticsco had been given before the index pregnancy to $19(40 \%) ?$ of the $\mathbf{4 8}$ patients; 21 had not been previously treated; and the treatment history of eight was unknown (table 1). Of the 13 patients with unsuspected acquired syphilis who were identified by antenatal screening, 11 were given penicillin during their current pregnancy; of these, five probably had active syphilis (table 2). Furthermore, seven of 16 patients previously treated for acquired syphilis received additional chemotherapy.

No live born child has so far shown stigmata of congenital syphilis. There were six $(11 \%)$ fetal losses (table 1) among the 57 pregnancies where the outcome

Table 1 Summary of findings of TPHA positive pregnancies

\begin{tabular}{llll}
\hline & Diagnosis* & \\
\cline { 2 - 3 } & Acquired syphilis & Congenital syphilis \\
\hline No of patients/pregnancies & $30 / 37$ & $2 / 3$ \\
Previous treatment/patients & $16 / 25$ & $2 / 2$ & \multicolumn{1}{c}{ Yaws or pinta } \\
Treatment during current pregnancy & $18 / 36$ & $1 / 3$ & $1 / 13$ \\
Outcome of pregnancy: & 31 & 2 & $10 / 19$ \\
Normal & $4 \dagger$ & 1 (intrauterine death at 30 weeks) & 1 (missed abortion) \\
Fetal loss & 1 (for non-venereal reasons) & 0 & 0 \\
Termination & 1 & 0 & 0
\end{tabular}

*Does not include three patients for whom questionnaires were not returned.

† Miscarriages at 24 weeks; 15 weeks and eight weeks (same patient); eight weeks. 
Table 2 Details for 13 patients with previously unsuspected acquired syphilis

\begin{tabular}{|c|c|c|c|c|c|}
\hline \multirow[b]{2}{*}{$\begin{array}{l}\text { Case } \\
\text { No }\end{array}$} & \multirow[b]{2}{*}{$\begin{array}{l}\text { Serology in } \\
\text { previous pregnancy }\end{array}$} & \multicolumn{4}{|c|}{ Current pregnancy } \\
\hline & & RPR titre & $\begin{array}{l}\text { Penicillin given } \\
\text { at: (weeks) }\end{array}$ & Outcome & $\begin{array}{l}\text { Probable nature } \\
\text { of syphilis }\end{array}$ \\
\hline $\begin{array}{r}1 \\
2 \\
3 \\
4 \\
5 \\
6 \\
7 \\
8 \\
9 \\
10 \\
11 \\
12 \\
13\end{array}$ & $\begin{array}{l}\text { VDRL negative } \\
\text { NK } \\
\text { VDRL negative } \\
\text { NK } \\
\text { VDRL negative } \\
\text { Primipara } \\
\text { VDRL negative } \\
\text { Primipara } \\
\text { Primipara } \\
\text { NK } \\
\text { VDRL negative } \\
\text { Primipara } \\
\text { Primipara }\end{array}$ & $\begin{array}{l}\text { Negative } \\
1 \\
\text { Negative } \\
\text { Negative } \\
4 \\
8 \\
\text { Negative } \\
4 \\
32 \\
8 \\
16 \\
8 \\
64\end{array}$ & $\begin{array}{c}35 \\
23 \\
\text { Not given } \\
\text { Not given } \\
21 \\
10 \\
14 \\
25 \\
<14 \\
13 \\
19 \\
8 \\
15\end{array}$ & $\begin{array}{l}\text { Normal* } \\
\text { Normal } \\
\text { Normal } \\
\text { Normal } \\
\text { Normal } \\
\text { Normal } \\
\text { Miscarriage } 15 \text { wks } \\
\text { Normal } \\
\text { Termination } 14 \text { wks } \\
\text { Normal } \\
\text { Normal } \\
\text { Miscarriage } 8 \text { wks } \\
\text { Normal }\end{array}$ & $\begin{array}{l}\text { Past treated } \dagger \\
\text { Latent } \\
\text { Past treated } \ddagger \\
\text { Past treated } \$ \\
\text { Late latent } \\
\text { Active } \\
\text { Past treated } \rrbracket \\
\text { Latent or treated } \\
\text { Early latent } \\
\text { Active } \\
\text { Active } \\
\text { Active } \\
\text { Active** }\end{array}$ \\
\hline
\end{tabular}

VDRL = Venereal Disease Reference Laboratory test.

NK = Multipara, but syphilis serology results in previous pregnancies not known.

* Baby given penicillin as a precaution because of delayed treatment of mother.

tInitially thought to be false positive by clinicians and treatment delayed.

ILaboratory diagnosis; treatment presumably not given because RPR negative.

§aboratory diagnosis; interpreted as false positive by clinicians.

TRecurrent miscarriages.

*\#IgM FTA-ABS positive (all other patients above not tested).

was known; five of these mothers had been treated with penicillin at some time either during their current pregnancy or previously, the exception being the patient who had yaws and a missed abortion. One further patient had a terminated pregnancy for reasons not related to the serological findings. Necropsies were performed on the 24 week and 30 week fetuses, and neither showed any evidence of congenital syphilis.

Although eight of the 10 cord blood samples tested were found to be TPHA and FTA-ABS positive, none of four additionally tested for IgM FTA-ABS was positive and all eight babies subsequently became seronegative.

The total cost of the 174643 antenatal TPHA screening tests performed during the study period, at 6 p per test, was estimated to be about $£ 10500$ - that is, about $£ 170$ per TPHA positive pregnancy identified.

\section{Discussion}

Specific tests for syphilis, such as TPHA, are gaining favour over reagin tests ${ }^{910}$ with screening laboratories because of their considerably lower incidence of false positive results and greater sensitivity. Although a positive TPHA confirmed by a FTA-ABS test is diagnostic of a treponematosis at some time, it does not necessarily imply that the patient is currently infectious as the serological reactions will remain positive long after the infection has been successfully treated. In some instances, however, it would be the clinical judgment that additional antibiotic treatment should be given during pregnancy to previously treated patients lest latent infection still existed. Indeed, further antibiotic treatment was given to seven of the 16 previously treated patients during this study. Furthermore, none of the serological tests can distinguish between syphilis and non-venereal treponematoses such as yaws, and many would choose to treat these patients in a similar manner in case syphilis was also present. ${ }^{14}$

A notable feature of this survey was that the serology results of two patients were incorrectly regarded as false positive by the clinicians, even though the FTA was positive and thus the results were unequivocal. The misinterpretation resulted in one patient not receiving treatment, and in the other it was delayed with the consequence that the baby was given precautionary antibiotics. Although on further review both patients had probably already received adequate treatment, this was not certain at the time. Another patient with unsuspected acquired syphilis did not receive antibiotics, possibly because the serology in this pregnancy suggested that the (French) patient might have had previous undeclared treatment. In this era of low infection rates these incidents emphasise the need for improved interdisciplinary communication.

The one in 1234 incidence of treponematosis found in the antenatal population of the Oxford region compares with one in 170 found by others in a London borough using TPHA ${ }^{10}$ and one in 2037 in New South Wales, Australia using the RPR method." The reduced unit cost of the Oxford RTC miniaturised TPHA test ${ }^{8}$ compares very favourably with that obtained by others. ${ }^{611}$ The cost for identifying each case of maternal syphilis would have been about $£ 350$.

The six fetal losses which occurred in the study group were not attributable to congenital syphilis (table 1). In four pregnancies fetal death occurred 
before the 18th week of gestation, before the time when transplacental infection is likely to occur'; necropsies on the two late abortions showed no evidence of congenital syphilis.

Although no case of congenital syphilis is known to have occurred in the catchment area during the study period, most of the cord blood samples tested gave positive reactions with the FTA-ABS test. It is presumed, however, that passively acquired IgG antibody from the mother was probably responsible for these reactions, ${ }^{3}$ and all of four tested were negative using a specific IgM assay.

Thirteen patients with previously unsuspected acquired syphilis were identified during this study, of whom five probably had active disease and one had early latent syphilis (table 2). Had these not been identified and given treatment the pregnancy might have resulted in congenital syphilis. Others have estimated $^{26}$ that out of every 10 affected pregnancies, the outcome would be two normal infants, three miscarriages or stillbirths, one neonatal death, two mentally handicapped children needing institutional care, and two others requiring special schooling. On this basis at least one child from our group might have required long term institutional care; the lifetime cost for this was estimated in 1985 to be about $£ 174000 .^{6}$ Notwithstanding the monetary and human costs of the other sequelae of congenital syphilis, an investment of about $£ 10500$ at 1988 prices for antenatal screening will have yielded considerable financial savings for the National Health Service.

We believe, therefore, that despite the current low incidence of congenital syphilis in the United Kingdom, it remains imperative to continue antenatal serological screening and to emphasise the importance of early, adequate treatment of those women found to have been infected. We would also agree with others that antenatal screening for syphilis remains highly cost effective. ${ }^{611}$

We thank those general practitioners, genitourinary medicine physicians, and obstetricians within the Oxford Region who contributed to this study.

\section{References}

1 Adler MW. Syphilis: clinical features. In: $A B C$ of sexually transmitted diseases. London: British Medical Association, 1984:38-48.

2 Stray-Pederson B. Cost benefit analysis of a prenatal preventive programme against congenital syphilis. National Institute of Public Health (Oslo) Annals 1980;3:57-66.

3 Nicol-Thin R. Lecture notes on sexually transmitted diseases. Oxford: Blackwell Scientific Publications, 1982:27-101.

4 Sequeira PJL. Syphilis. In: Jephcott AE, ed. Sexually transmitted diseases. London: PHLS, 1987:6-22.

5 Chattopadhyay B. Prevention of congenital syphilis. Br J Hosp Med 1988;40:68-70.

6 Williams K. Screening for syphilis in pregnancy; an assessment of the costs and benefits. Community Med 1985;7:37-42.

7 Centre for Disease Control. Current trends: increases in primary and secondary syphilis in the United States. $M M W R$ 1987;36: 393-6.

8 Puckett A, Pratt G. Modification of the system of screening for antisyphilis antibodies in a blood transfusion centre, featuring a miniaturisation of the Treponema pallidum haemagglutination assay. J Clin Pathol 1982;35:1349-52.

9 Puckett A, Pratt G. Syphilis screening in the Blood Transfusion Service: a report of four years experience with the Treponema pallidum haemagglutination assay and the subsequent development of a rapid spin method. J Clin Pathol 1987;40:1337-9.

10 Wright DJM, Gerken A. Antenatal screening for syphilis. $\mathrm{Br} J$ Vener Dis 1981;57:147-8.

11 Bryce RL, Pritchard RC. The cost of routine antenatal screening for syphilis. Aust NZ J Obstet Gynaecol 1981;21:211-3.

Requests for reprints to: Mr P J Bowell, Head of Antenatal Serology Department, Regional Blood Transfusion Centre, John Radcliffe Hospital, Headington, Oxford OX3 9DU, England. 